\title{
NIETZSCHE O LA ELEGÍA A LA CULTURA ESTRANGULADA
}

\author{
Pablo HeRMida LEZCANO \\ Dpto. De Filosofía y Filosofía Moral. UNED
}

«Lieber verwesen als ein Weib sein, das nicht reizt» (Es preferible pudrirse a ser una mujer que no seduce) F. NIETZSCHE, Humano, demasiado humano II

Introducción: Sublimidad y ocaso del arte

Cabría hablar, en una primera aproximación, de dos actitudes básicas en Nietzsche con respecto a la estética. El joven Nietzsche aparece en El nacimiento de la tragedia (NT) como un impetuoso culminador de la filosofía idealista y, en concreto, como un ardiente abanderado del Absolutismo estético, a través de tesis exaltadoras de lo estético como única legitimación y justificación posibles del mundo y de la existencia humana, encuadrándose así en una tradición que se remonta a Schelling (itinerario cuyas etapas, desde el Absolutismo Idealista hasta el Esteticismo, se cubren con finura en SM, especialmente en los capítulos V y IX). El segundo período, en cambio, vendría marcado por un radical cambio de actitud que, bajo el signo del desengaño y la decepción,

Éndoxa: Series Filosóficas, $n^{0} 6,1995$, UNED, Madrid:

Pablo Hermida Lezcano: Nietzsche o la elegia a la cultura estrangulada.

pp. 299-321. 
se traducirá en la denuncia de la agonía y la impotencia, la destrucción de lo estético $\mathrm{y}$, en definitiva, el diagnóstico de la muerte del arte, consigna que servirá de barómetro con que medir y tornar comprensible el grado de entusiasmo, excitación, fe, desencanto, decepción o rechazo de Nietzsche con respecto al valor real o potencial de lo estético y lo artístico.

El tránsito del primer período al segundo viene marcado biográficamente por un decisivo acontecimiento cultural: el verano de Bayreuth (del año 1876), al que tantísimas y tan recurrentes reflexiones habría de dedicar Nietzsche. El análisis del fracaso de Bayreuth suministra a Nietzsche las fatales claves con que resolver intelectualmente el macro-problema de una cultura europea en deca-dencia y amenazada por el reino de la barbarie. El proyecto de redención, que según Nietzsche se había ido fraguando en torno a la música de Wagner, acaba en auto-traición, en renuncia y en impotencia.

Conviene tener presente ya desde ahora la enorme ilusión intelectual que Nietzsche había depositado en el programa wagneriano, pues sólo así podrá hacerse comprensible la honda repercusión y la capital importancia atribuida al fracaso de Bayreuth. Wagner no es un mero compositor decimonónico, sino un autor emblemático, un genio proyectado retrospectivamente por Nietzsche hasta el espíritu mismo de la tragedia griega y proyectado asimismo hacia el futuro, en la base de un programa de restauración de la amenazada cultura europea. Es más, puede afirmarse que, a través de Wagner (como, en cierta medida, a través de Schopenhauer), se conectarían para Nietzsche el pasado y el futuro de nuestra cultura, en un intento de rescatar su esencia trágica, lo que equivale a mantener viva la irreductible tensión entre generalidad e individualidad. El garante de semejante tensión esencial de nuestra cultura a lo largo de la historia no es otro que el arte, cuya función es precisamente la de velar para que el arco no se rompa (Damit der Bogen nicht breche, ist die Kunst da. [CI (IV)]). Esta función sería la desempeñada paradigmáticamente por la tragedia griega y la que presumiblemente estaba llamado a desempeñar, desde un crítico 
momento histórico, el drama musical de Wagner, si bien éste acabaría por pervertir su papel desviándose por los senderos de un cristianismo nihilizador y una sintonización perfecta con los ideales imperialistas del Reich, en detrimento de toda individualidad.

Empieza a intuirse ya que el amargo "no a Wagner" es un núcleo de condensación de otras muchas negativas, que implican otras tantas decepciones ante caminos truncados. En todo caso, me parece que un problema tan apasionante como difícil a la hora de examinar las actitudes estéticas de Nietzsche es el de fijar en sus justos términos, en cada caso, la relación entre la radicalidad y generalidad de sus tesis y la particularidad de ciertos acontecimientos biográficos y/o históricos. Encontramos este desafío, a nivel biográfico, en su primitiva veneración a Schopenhauer y a Wagner. A parte de lo que ambos representen en el dominio de la filosofía o la música, son elogiados como genios, y han de ser conectados con la extraordinaria importancia conferida por el joven Nietzsche a la figura del genio, devaluada más tarde desde el Nietzsche "ilustrado". Como ejemplo de acontecimiento clave vivido por Nietzsche, sirva el ya aludido verano en Bayreuth. En cuanto a la lectura de los eventos de la historia de nuestra cultura, hay que destacar la contextualización de sus tesis absolutizadoras de lo estético en el marco de la Grecia clásica - sede de la tragedia-, con la subsiguiente fijación de los procesos degenerativos en torno a ciertas figuras clave, tales como Eurípides y, sobre todo, Sócrates.

Otro significativo ejemplo de generalización desde lo particular es el paradigmático papel representado por la música a la hora de realizar análisis y formular diagnósticos sobre el estado de salud o enfermedad del arte. La importancia de esta supravaloración crece desde el momento en que el grado de vigor o debilidad de toda la situación sociocultural se describe, en gran medida, como deudor del estado en que se encuentre el arte. Pues bien, la supremacía de lo musical responde a convicciones nietzscheanas que aparecen ya expuestas en las páginas de NT, y que están muy 
vinculadas a la confrontación entre los dos espíritus o talantes contradictorios que allí se describen, a saber: el espíritu apolíneo y el dionisíaco. Sin necesidad de abundar en tesis bien conocidas, recordaremos sólo que lo musical es inherente a la voz de un Dionisos embriagador, que resuena ancestral desde lo más profundo, desde el caos del ser original, de la unidad primitiva, rasgando todos los velos de la apariencia, de lo individualizado: del hermoso y somnoliento rostro de Apolo. Desde el tiempo presente, la trascendental misión que Nietzsche reserva a la música no se ha devaluado; antes bien, ha proyectado sus esperanzas sobre un nuevo blanco: las composiciones de Wagner, primero con un devoto entusiasmo, luego con la amargura del desencanto. En todo caso, el instrumento de medida permanece.

\section{¿Quiebra o continuidad?}

¿Muerte del arte? El traumático cambio de signo de las convicciones estéticas nietzscheanas reviste a mi juicio una radicalidad sospechosa, una enigmática inversión de términos demasiado abrupta como para que la descripción de la evolución en términos de sucesión de dos fases antitéticas resulte convincente. Así, por ejemplo, uno de los problemas que se nos plantean enseguida es la dilucidación del tipo de ciencia que Nietzsche defiende a capa y espada en ese segundo período socratizante o "ilustrado". Como tendremos ocasión de ver, la ciencia diseñada es, antes que otra cosa, crítica desenmascaradora de actitudes idealistas. Se trata de una "gaya ciencia", difícilmente equiparable al ideal de cientificidad proclamado por el Positivismo, que a menudo se ha pretendido reconocer en esta vehemente reacción nietzscheana contra la metafisica del artista suscrita en NT.

Para paliar la rotundidad de una descripción simplista en términos de ascenso-descenso antitéticos, habrá que rastrear y enfatizar los elementos de continuidad. En este sentido, autores como G. Deleuze o E. Fink se esmeran en preservar un fondo 
estable de ciertas convicciones nietzscheanas de partida, que garantice la coherencia e inteligibilidad de las evoluciones más rompedoras, leídas ahora a la luz de la peculiar interpretación que Nietzsche hace de la cultura occidental, de su origen y de su presumible porvenir. No obstante, y por muchos esfuerzos que se hagan por subrayar los elementos de continuidad, existe en la evolución nietzscheana una indiscutible quiebra, marcada por la inversión cuasi-simétrica de una serie de actitudes y valoraciones, entre las que destaca la operada en la valoración correlativa del arte y de la ciencia, y del peso y la significatividad del uno y de la otra en el todo sociocultural. En líneas generales, después de un considerable deambular por los textos nietzscheanos, tengo la impresión de que muchos de sus cambios de actitud, sus reformulaciones, nuevas perspectivas, tomas de posición y consignas obedecen a razones estratégicas y de crítica desenmascaradora, donde el acento recae una y otra vez en el polo de lo criticado (la cultura occidental, sus errores pasados, sus formas degeneradas de enfilar el porvenir, el estrangulamiento de los instintos y las fuerzas más fértiles...), y no tanto en el del instrumento empleado como herramienta para la crítica, la reconducción y la redención (ya se trate de un arte dionisíaco o de una gaya ciencia).

Acaso la trayectoria de Nietzsche pudiera ser descrita como una sucesión de ensayos destinados a salvar la cultura europea, previamente diagnosticada como decadente y enfermiza. Acaso estos ensayos no han supuesto sino un continuo "tomar el pulso" a diversos "redentores potenciales", ensayos que habrían acabado vez tras vez en el fracaso y la decepción consiguiente. Acaso las diversas tentativas han estado siempre guiadas por la intuición de la esencia trágica de nuestra cultura y quizás Nietzsche siempre presintió que el respiradero idóneo de esta cultura no podía ser otro que un arte trágico-dionisíaco, capaz de dar cancha al juego de la tensión primordial. Pero entonces, una fatal constatación: por razones esenciales o coyunturales nuestra cultura se delata incapaz de reconducir su trayectoria hacia su vocación trágica. No se trata sólo de que el arte dionisíaco pierda su posición privilegiada de 
organon, sino que ni siquiera parece poder albergarse en un modesto segundo plano. Sería entonces cuando, ante la alternativa de resignarse a convivir con unas formas artísticas alienantes, degeneradas y amparadas por una religión y una metafísica nihilizantes, Nietzsche optaría por cambiar de estrategia dándole a su crítica el nombre de ciencia (de una ciencia muy peculiar, alegre y jovial), cuyo principal cometido sería la denuncia y el desenmascaramiento de todas esas actitudes débiles y encubridoras, despojadoras de aquello que el hombre tiene de más valioso, a saber: lo humano, demasiado humano.

Desde esta propuesta reconstructiva de sus tesis estéticas, se hacen precisas todas las cautelas a la hora de interpretar el "socratismo" y la "ilustración" del segundo Nietzsche. No se trata bajo ningún concepto de una fe ciega en la razón, el progreso y la ciencia sino que, como gráficamente lo expresa Fink, estamos ante una ilustración "ilustrada con respecto a sí misma" (EF, pp.61-62). Por su parte, el problema de la significación de Sócrates me parece uno de los más complejos en nuestro contexto. En un principio, Sócrates es para el primer Nietzsche el representante preclaro de la primera muerte de la tragedia, aquél que estrangula el espíritu dionisíaco al hacerle estrellarse contra el muro de lo consciente y de lo lógico. Menos obvia me parece sin embargo la identificación del cambio de talante de Nietzsche con su presunta afiliación al socratismo antaño desdeñado. Como afirma Deleuze, "Sócrates es el "hombre teórico", el único verdadero contrario del hombre trágico". Particularmente, tengo serias dudas sobre la posibilidad de que en algún momento Nietzsche - aun desde su "ilustración" haya dejado de verle como tal

\section{Trágicas muertes para escribir la historia}

Podría definirse El nacimiento de la tragedia como la exposición nietzscheana de la célebre metafísica del artista. A través de la conocida consigna que erige a lo estético en único legitimador 
potencial de la existencia humana y del mundo, se está postulando una visión absolutizadora de lo estético, muy en la línea de las omniabarcantes pretensiones del idealismo romántico precedente. El arte es considerado organon de la filosofía, símbolo metafísico y acontecimiento cósmico. Acaso lo más atrevido de estas tesis absolutizadoras sea la pretensión de convertir la estética en una ontología, con todas las implicaciones que ello comporta. El núcleo de condensación de lo artístico será lo trágico y la investigación estará guiada por pretensiones esencialistas, que pretenden ver en lo trágico la naturaleza misma de lo real. Reparemos ya en las repercusiones que estas tesis han de tener a la hora de interpretar la historia de la cultura, incluidos el presente y el futuro de la Alemania que Nietzsche vive. Si la realidad es trágica en su esencia, entonces desoír, ahogar o violentar lo trágico vale tanto como desvirtuar o distorsionar el carácter definitorio de lo real. La cultura que así obre será forzosamente tarada, degenerada, empobrecida y falta de vigor y de brillo. La atribución al arte del rango de organon de la filosofía no es por tanto sino una consecuencia gnoseológica necesaria de la postulación de lo trágico como principio ontológico fundamental.

Como sabemos, la metafisica de artistas es expuesta por Nietzsche a propósito de la razón de ser y la suerte destinada a la tragedia griega clásica. En ese contexto, el instrumento interpretativo privilegiado es la confrontación del espíritu apolíneo y el dionisíaco, ambos en pugna constante, cuya indefectibilidad es la esencia misma de lo trágico. Esta oposición de instintos, ligados a divinidades, reviste de entrada un carácter fisiologicista, vinculando a las divinidades implicadas con las experiencias humanas del sueño y la embriaguez. A partir de ahí, se va operando el tránsito hacia las esferas ontológico-cosmológica y existencial. Se plantea así la eterna tensión entre la verdad y la apariencia, entre la profundidad y la superficie, entre la unidad del caos primigenio y la ficción del principio de individuación. El arte transfigura la existencia, haciendo llevaderos todos los combates y emitiendo como resultado un veredicto de afirmación de la vida (que es cier- 
tamente la afirmación en un tipo especial de pesimismo, muy distinto del pesimismo derrotista romántico), en contra de toda tendencia nihilista. Uno de los temas recurrentes en este contexto es el de la relación entre el arte y la inconsciencia y, recíprocamente, el efecto aniquilador que la conciencia ejerce sobre el arte, lo que conecta ya con el problema de las sucesivas muertes de la tragedia.

La consideración del tópico de la muerte del arte en Nietzsche ha de fijar su escenario de batalla privilegiado en la muerte de la tragedia 0 , para ser más precisos, en las repetidas muertes de ésta. Esto es así en virtud del ya examinado papel nuclear de lo trágico, cuyos eternos afanes por emerger e imponerse se van topando con diferentes rivales a lo largo de la historia de la cultura occidental. Me parece que G.Deleuze subraya con gran habilidad esta continuidad del acoso a lo trágico en las siguientes líneas: "¿a qué llama "trágico" Nietzsche? Nietzsche opone la visión trágica del mundo a otras dos visiones: dialéctica y cristiana. $O$, con mayor precisión, la tragedia tiene tres formas de morir: la primera vez muere debido a la dialéctica de Sócrates, es su muerte "euripidiana". La segunda vez a causa del cristianismo y la tercera bajo los golpes conjuntos de la dialéctica moderna y de Wagner en persona." (GD, p.20). Unas líneas después, Deleuze recuerda que Nietzsche habría descubierto "la incapacidad congénita de la dialéctica y del cristia-nismo de vivir, de comprender, de pensar lo trágico". Llamo sobre todo la atención en este momento sobre el adjetivo "congénita", pues sería una respuesta posible a lo que ya hemos planteado como cuestión abierta, a saber: las razones esenciales $\underline{0}$ coyunturales por las que nuestra cultura vetaba lo trágico. Pues bien, a la luz del recordatorio de Deleuze, tendríamos buenas razones para sos-pechar que se trata de razones esenciales o inherentes a nuestra propia fisonomía cultural, habida cuenta de sus raíces e ingredientes.

De estas tres muertes históricas del arte por antonomasia nos interesa ante todo la descripción de la primera, la "euripidiana", que constituye uno de los cometidos primordiales de NT. La 
irrupción de Sócrates - preparada por el sesgo que la tragedia toma con Eurípides- es una auténtica bomba, que provoca una catastrófica explosión liberadora de la conciencia, la teoreticidad y la lógica calculadora. Lo más significativo a mi juicio es la reiterada acusación nietzscheana de intrusismo e incomprensión. Según esto, todo socratismo supondría una incursión ilícita desde la ignorancia en esferas que no son de la competencia del hombre teórico. El precio de este intrusismo es el relevo del vigoroso, profundo y afirmador pesimismo trágico-dionisíaco por un endeble optimismo socrático.

\section{Religión, arte, ciencia: del relevo a la fragmentación}

Como bien es sabido, la obra Humano, demasiado humano es interpretada retrospectivamente por el propio Nietzsche, desde Ecce Homo, como "el monumento de una crisis". Abundan en ella los parágrafos redactados en el tono más crudamente positivista à la Comte, en una desconcertante inversión de perspectivas, principios y convicciones pasadas. Sin embargo, tan tajante cambio de signo no puede por menos de resultarnos sospechoso e invitarnos a una cautelosa consideración para evitar polarizaciones precipitadas. La forma de evadirse de estas encorsetadoras dicotomías entre el joven Nietzsche de NT y el posterior autor de $\mathrm{HdH}$ es, como ya se sugirió en la Introducción, no perder jamás el norte de las expectativas nietzscheanas de cara al proyecto cultural de Occidente, leído en su continuidad histórica. Por esta razón, la exploración del "positivismo" nietzscheano me parece indesligable de su rigurosa tarea de diagnóstico de la decadencia cultural, así como de las esperanzas depositadas en Wagner ( $y$ luego frustradas), como saneador potencial de la cultura del presente y del porvenir.

De entrada, para ir acotando el sentido del "positivismo" nietzscheano, me parece una conveniente estrategia heurística su vertebración en torno a dos vectores principales, que denominare- 
mos vector geológico-evolutivo y vector arqueológico-ecológico respectivamente. De estas dos pautas, la primera muestra un rígido carácter de evolucionismo comtiano, basado en la sucesión de estadios, en tanto que la segunda viene a compensar esta rigidez con un talante menos hermético, más integrador, comprensivo y sensible a los desequilibrios y a las taras y contradicciones constatables en el complejo sociocultural.

Comenzando con el primer vector, la religión, el arte y la ciencia constituyen eslabones sucesivos de una cadena evolutiva lineal que implica procesos de superación, perfeccionamiento y asunción de las herencias del período precedente. No deja de ser sintomático a este respecto que Nietzsche parafrasee en más de una ocasión el postulado evolucionista según el cual la ontogénesis es la recapitulación abreviada de la filogénesis. Paráfrasis que se detecta en la atribución al proceso de maduración de cada individuo de las mismas fases evolutivas propias de la comunidad cultural: de la religión al arte y de éste a la ciencia.

Creo que se comprenderá por qué hablamos de perspectiva geológica, pues en realidad se trata tan sólo de asumir la metáfora de la superposición de estratos geológicos a la hora de definir la cultura humana. En este tránsito de la religión al arte y de éste a la ciencia, es de destacar el papel de intermediario desempeñado por el arte, que permite acceder a la ciencia mediante un suave tránsito, para evitar el de otro modo escabroso y traumático ingreso desde la religión. En virtud de esta labor mediadora, al ocaso de las religiones corresponderá por necesidad, a modo de réplica, el ulterior ocaso del arte. Sin embargo, pese al aroma declaradamente positivista de estas tesis, conviene reparar en la peculiar naturaleza de la ciencia que se sitúa en la línea de llegada. Lejos de responder al ideal positivista de una ciencia unificada, se vislumbra como un concepto sustancialmente asimilable a los de critica, denuncia y desenmascaramiento. Habrá de ser una ciencia audaz, perspicaz, penetrante, al tiempo que jovial y "gaya". El juego de estos conceptos se tornaría mucho más inteligible si situásemos en su base el alarmante diagnóstico del presente y el 
porvenir de la cultura, teñido por la decepcionante constatación de la décadence.

El segundo vector, el arqueológico-ecológico, remite en cambio a la complejidad de la cultura, derivada de la de cada uno de los seres humanos que la integran. En éstos, la superposición de estratos no puede ser una obra de ingeniería perfecta y sin fisuras. De hecho, nunca hay pasados plenamente enterrados porque nunca hay transformaciones radicales de la naturaleza humana. Antes bien, ésta presenta una serie de disposiciones, facultades y capacidades inherentes que deben ser tenidas en cuenta en alguna medida, por más que se primen ciertas dimensiones en detrimento de otras. En caso de intolerables descuidos de alguna faceta o dimensión, empiezan a detectarse desequilibrios, fallas, descompensaciones, que van generando individuos mutilados, parcialmente arruinados. Y otro tanto puede decirse de la propia cultura que deja flancos desatendidos.

Desde luego en Nietzsche abundan los textos destinados a justificar la necesidad de seguir dando cabida a las manifestaciones artísticas, metafísicas y religiosas, por mucho que se evolucione hacia el dominio de una cierta cientificidad. Doble prevención, pues, contra el desequilibrio comunitario y personal. Pero sucede que, si bien estas pervivencias compensadoras y nostálgicas resultan necesarias, constituyen asimismo un fardo que, en ocasiones, se vive como algo difícilmente acarreable. Sus descripciones a este respecto rozan el esbozo de actitudes esquizoides, compartimentadoras de la personalidad, pues derivan hacia la fragmentación de la persona en compartimentos-estanco, así como a la de sus actividades y a la de las propias artes, todo ello encaminado a la contemplación de un hombre escindido, distante de todo asomo de integración armónica de facultades. Incluso es curioso que, en ciertos momentos, el tono de las lamentaciones de Nietzsche se asemeje a las conocidas denuncias del joven Marx.

En todo caso, pese a las amenazas de esquizofrenia cultural, Nietzsche aboga decididamente por la preservación conciliadora aunque fragmentaria, y los extremos son temidos como caída en 
la barbarie. Que estas diversas facetas y dimensiones estén integradas y no meramente yuxtapuestas, no pasa de ser -como el propio Nietzsche reconocerá- una visión.

\section{Arte como engaño. Formas artísticas degeneradas}

A lo largo de las obras de Nietzsche cabe distinguir dos sentidos principales en los que éste habla del arte como engaño y de los artistas, por tanto, como "engañadores". Una vez más, al hilo de la confrontación de los espíritus apolíneo y dionisíaco en NT, del lado del primero se alinean las tendencias al disimulo y a la falsificación, constitutivas de una apariencia que aporta al arte, a modo de ingrediente, aquello que torna la existencia soportable y llevadera, al contrarrestar los efectos turbulentos y conmovedores de lo dionisíaco. Puede decirse que, en su contexto, esta suave y bella apariencia apolínea cumple una misión legítima y que sólo su extralimitación será contestada por Nietzsche.

En este sentido, el "arte engañoso" puede verse en segundo lugar como el fruto de los excesos ilícitos del instinto apolíneo, con algún que otro añadido en confabulación. Cuando todo terreno ha sido usurpado al vigoroso arte trágico-dionisíaco, sólo restan ciertas manifestaciones débiles e irrisorias, mustias, que Nietzsche tachará de engañosas en el sentido más peyorativo del término. Correlativamente, los artífices de estas flaquezas serán calificados de artistas mentirosos, engañadores, sembradores de confusión y desviadores-derrochadores de energías. En estas coyunturas de debilidad, se adhieren al arte todo tipo de formas espúreas, y éste tiende a nutrirse con cobardía en las fuentes consoladoras y falsificadoras de la religión y la metafísica idealista. Se comprende así el afán nietzscheano por recurrir, ante este estado de cosas, a una ciencia que es crítica desenmascaradora. Si algún arte es visto por Nietzsche como alienante, éste es desde luego el arte engañador contra el que arremete en numerosos parágrafos de Humano, demasiado humano. 
Muy en relación con el tema precedente se encuentra el problema de la jerarquización de las formas artísticas, atendiendo a criterios de pureza, integridad, vigor o generalidad. Se detecta, por un lado, la oposición entre el Arte en general y las distintas artes particulares. En esta distinción, el Arte aparece equiparado a la Filosofía, en la medida en que ambos persiguen al tiempo la mayor generalidad y profundidad, a diferencia de los saberes parcelarios y acotados. Esta oposición conecta con el tópico filosófico que se remonta, cuando menos, a Aristóteles, y que propone a la "ciencia primera" como el saber de los saberes.

Asimismo se distingue entre un pequeño y un gran arte, adoptando como criterio de oposición el grado de exigencia, dedicación y compromiso requeridos por uno y otro. Nietzsche vincula por lo demás esta dicotomía al contexto material de las condiciones de producción, con sus repercusiones prácticas al hilo de la cantidad y calidad del tiempo invertido en el trabajo y en el ocio. De segundo grado es considerado ese arte que juega el papel de distracción y esparcimiento para los agotados trabajadores. Este es un aspecto de la crítica general de Nietzsche a la sociedad y al arte burgueses.

En otros casos, se prescinde de la referencia explícita a un ideal de arte puro, para formular distinciones, preferencias y jerarquizaciones en el paisaje de las formas artísticas al uso. Así, se ejemplifica con el teatro de la época como una de las formas artísticas decadentes y degeneradas, con despectivas críticas a los comediantes. En cualquier caso, se explicite o no, siempre tiene presente Nietzsche un modelo rector, un patrón de pureza para el arte, que reclama buenas dosis de vigor y esfuerzo, lo que le confiere un necesario carácter elitista, fuera del alcance de las gentes débiles. Esto se plasmará en la aristocratizante consigna "arte para artistas". 


\section{De Grecia a Alemania: Itinerario de una cultura decadente}

El paso por el positivismo sería para Nietzsche una visita fugaz y de puntillas. Tal y como le ve, por ejemplo, Eugen Fink, Nietzsche "no es un utopista, uno de esos hombres que pretenden mejorar el mundo y traerle la felicidad; no cree en el "progreso". Tiene una oscura profecía para el futuro, es el mensajero del nihilismo europeo." (EF, p.10). Al margen de la opinión de Fink, parece indudable que Nietzsche somete el orden sociocultural de su tiempo a un sombrío análisis y todos sus pronósticos sobre la evolución de los acontecimientos, por más que en muchos casos intenten plantear caminos de redención y restauración, están teñidos de negros presagios de degeneración y decadencia de nuestra cultura occidental. Es precisamente en el seno de esta oscura tarea de diagnosis donde debe enmarcarse el tópico del ocaso del arte en Nietzsche, como síntoma troncal de la vocación de derrota de una cultura, allí donde los últimos cartuchos de esperanza, de wagneriana impronta, acaban por humedecerse y nunca llegan a transformarse en un estallido reactivador. No obstante, Nietzsche se esmera por mantener, a pesar de todas las hostilidades, una vía abierta para sanear la cultura. Poco a poco irán cristalizando sus esperanzas y tomando cuerpo en la figura de un Zaratustra que, en tanto que ideal, se antoja mucho menos vulnerable que esos espejismos que resultaron ser los genios Schopenhauer y Wagner.

Son numerosos los exponentes de la decadencia. Así, por ejemplo, Nietzsche se referirá a menudo al optimismo débil y a las frágiles organizaciones utilitaristas y de democrática racionalidad. Estos procesos de declive son paralelos en la Grecia clásica y en la Alemania de su tiempo. De ahí que, nunca triunfalista, Nietzsche se esfuerce en subrayar las dificultades de toda tentativa restauradora, allí donde la cultura y el "gran arte" caminan por senderos divergentes, que tornan casi imposible el renacimiento del vigoroso arte trágico-dionisíaco. 
Ante situación tan precaria como la descrita, Nietzsche apuesta por una reforma educativa radical, que comenzará por ser elitista y selecta, para ir ganando sólo después generalidad. El arte para el que se educará será también minoritario en un principio, y se caracterizará, entre otras cosas, por una vocación integradora y sistemática, donde los componentes estético y ético no cabalguen por separado sino en armonía. En más de un lugar encontramos esta pretensión integradora de los distintos elementos, que recuerda el afán kantiano de sistematicidad bajo un propósito común, y que aquí está destinado a hermanar las esferas de la ética, la estética y la política.

Situábamos antes con Deleuze la tercera muerte de la tragedia en el contexto de la dialéctica moderna y de la producción musical de Wagner. Precisamente el tema de la muerte de lo trágico sirve de hilo conductor para una lectura coherente de la historia de Occidente interpretada como un continuum. Las sucesivas muertes de lo trágico dan pie a Nietzsche para establecer paralelismos en los procesos degenerativos clásico y moderno. Dado el firme entronque y la significatividad de lo musical en el todo cultural, la tragedia, el drama musical clásico y moderno revisten para Nietzsche una doble relevancia: por un lado, la significación propiamente estética $y$, por otro $-\mathrm{y}$ sin que ambos aspectos puedan desconectarse- una relevancia ético-política. El rastreo de ambas dimensiones encuentra, como ha puesto de manifiesto entre nosotros el minucioso análisis de $\mathrm{JQ}$, una buena fuente en las Consideraciones Intempestivas, especialmente en la cuarta (Richard Wagner en Bayreuth), donde puede seguirse la pista de las relaciones entre "Grecia" y "Alemania".

El denominador común a estas reflexiones se cifra en la necesaria vocación de actualidad o vigencia de lo trágico, perpetuamente delimitado en su territorio por la frontera con el socratismo. En la medida en que persevera el influjo socrático, se presume para el arte una misión heroica que apunta al infinito. El superar airosos la precariedad del presente y encarrilar un futuro prometedor vale tanto como propiciar el renacimiento de lo dionisíaco. Con 
este fin, urge estirpar el carácter obnubilante de la música romántica, que embelesa porque adormece y debilita, generando un tipo de hombre equiparable al que resulta del paso del hombre trágico-esquíleo al hombre jovial-alejandrino. La apuesta por una "edad trágica" venidera tiene como uno de sus pilares básicos la confianza en el poderío de la música alemana (Bach, Beethoven, Wagner). Cuando este pilar se desmorone, será preciso trasladar las ilusiones a un nuevo soporte, que entonces empezará a llamarse Zaratustra.

Sin embargo, en uno de los pasajes de Arte y artistas nos topamos con una interesante prevención en la que Nietsche ya nos pone alerta sobre los peligros de un espíritu dionisíaco que renazca con desenfreno, de un modo incontrolado y cuya resultante sería un exponente más de ese "reino de la barbarie" al que tantas veces alude. Una vez más, por tanto, se constata que el próspero porvenir del arte depende del equilibrio de instintos contrapuestos que constituye el juego trágico, y que la extralimitación de Apolo o de Dionisos acarrea consecuencias igualmente nefastas para el arte y la cultura.

\section{Contra Wagner y el Romanticismo; adiós a los genios}

En esencia, la relación entre Nietzsche y Wagner puede ser descrita como la caída desde la admiración, la veneración ilusionada y la apuesta esperanzada hasta el desengaño y desencanto más radicales y dolorosos. Nietzsche vive la disolución de este espejismo con toda la amargura de quien se ha implicado vitalmente hasta la médula y quien ha proyectado en buena medida sus convicciones teóricas y sus intuiciones acerca del presente y el porvenir de Europa sobre el venerado compositor. Wagner empieza siendo una apuesta fresca, condensadora de las ilusiones de una época y restauradora de la imagen del artista-creador. Su misión habría de ser la revolucionaria transformación del contexto musical aletargado, mediante formas y creaciones de primer orden, 
que sentasen las bases para la afirmación y la transmutación. Lejos de conquistar estas metas, Wagner desvía decepcionantemente su trayectoria, sucumbiendo en los brazos del pesimismo romántico y del nihilismo cristiano, un pesimismo y un nihilismo radicalmente opuestos al vigoroso pesimismo que Nietzsche pretende encarnar y reivindicar.

La plasmación en sentencias de este ascenso-descenso adopta las formas más elocuentes, gráficas y expresivas, que en sus aforismos rezuman una ironía y un tono burlón, pero detrás de todo el sarcasmo se adivina siempre una amargura y un resentimiento inauditos. Así, Nietzsche refiere sus experiencias con Wagner en términos de enfermedad e infección contagiosa, con la consiguiente terapia y curación que supuso el distanciamiento posterior. La reacción contra Wagner impone a Nietzsche, a modo de penitencia para una perfecta terapia, el radical desdeño y apartamiento de la música romántica. Sin embargo, Nietzsche mantiene la frialdad necesaria para descargar a Wagner de toda responsabilidad injustamente atribuida. En este sentido, se esmera en subrayar la perfecta compenetración entre el compositor y la atmósfera cultural imperante. Por respirar dicho aire enrarecido, Wagner es absuelto de casi todas sus culpas y es visto como una víctima más. El auténtico peligro radicaría en realidad en ese pernicioso germen de degeneración que ha invadido a Alemania y que avanza de modo alarmantemente contagioso, infectando todo cuanto halla a su paso. Si de algo cabría culpar a Wagner sería precisamente de haberse dejado engullir por tan abrumadora ola. En realidad, Wagner no sería más que un preclaro exponente de la Modernidad, aquejado de sus mismas taras y debilidades.

Una particularización o condensación más concreta del ascensodescenso en la actitud de Nietzsche con respecto a Wagner es la que representa el verano de Bayreuth. Se trata del momento paradigmático, del punto crucial en el que se toma el pulso a la fiabilidad de las perspectivas renovadoras de la música wagneriana. Al interpretar Nietzsche este proyecto como un estrepitoso fracaso, quedan abiertos sus ojos al océano de la decepción. La 
experiencia debió de ser un arrojarse al vacío carente de referencias, de modelos que tornasen mínimamente verosímil el proyecto nietzscheano de redención de la cultura. La cultura había de redimirse por el arte privilegiado, la manifestación artística por antonomasia $y$, sin embargo, este arte se exhibe agonizante, moribundo. Su agonía es la agonía de Alemania, la agonía de Occidente. J.Quesada, apoyándose en afirmaciones del propio Nietzsche en su IV Intempestiva, nos ayuda a interpretar Bayreuth en toda su trascendentalidad y gravedad:

Bayreuth estaba llamado a ser, en la emoción de Nietzsche, el sanctasanctórum de una revolución cultural que transfiguraría al europeo.(...) pues no es meramente "artística" la revolución que pretendía Bayreuth (...) Bayreuth pretendía ser algo así como el estandarte de guerra contra la pseudoilustración. (JQ, pp. 289291)

Como contrapunto de las solemnes formulaciones estéticas del primer Nietzsche, en clave metafísica y con hondas implicaciones ontológicas y gnoseológicas, podrían aducirse pasajes que ilustran sus tentativas de apuntar hacia una estética de corte fisiologicista, es decir, hacia una visión de la estética como fisiología aplicada. En más de una ocasión presumirá que es esta estética fisiologicista la que le suministra los argumentos para despreciar la música de Wagner, en virtud del malestar físico y la incomodidad que ésta le provoca.

El culto profesado al genio, en tanto que personaje cargado de un poderoso simbolismo y valor metafísico, se halla estrechamente vinculado, como es sabido, a la metafísica del artista que se desarrolla en NT . Los únicos atisbos de modestia y pequeñez derivarían del hecho de que el artista no sea sino un instrumento de las potencias creadoras cósmicas, en una réplica de la perpetua lucha de instintos confrontados. En efecto, si asumimos la unicidad productiva del arte como acontecimiento cósmico, el artista ve reducida automáticamente su actividad a una "endeble repetición de la poiesis más imaginaria de la vida universal" (EF, p.36). Sin 
embargo, esta vinculación al fondo cósmico creador supone, antes que otra cosa, un argumento más a favor del ensalzamiento del genio, ya que éste aparece por esta vía tanto más distinto de los demás hombres.

Pues bien, la evolución de la percepción nietzscheana del arte, ya en su segundo período "ilustrado-positivo", implica una reacomodación del juicio sobre el genio. Esta evolución puede fijarse tanto en un nivel impersonal o categorial como en el terreno de los modelos personales, siendo dignos de mención a este respecto los nombres de Schopenhauer y Wagner. El primer nivel, más abstracto, es directamente deudor del relevo de la óptica del arte por la óptica de la ciencia. Desde la nueva perspectiva, y siempre en la línea de oposición al idealismo romántico, se arremete contra las tres formas de la grandeza humana autoalienada: el santo, el artista y el sabio. Esto es coherente con la tarea desenmascaradora de ilusiones y espejismos, alli donde todo es, en puridad, humano, demasiado humano. Por ello resulta perfectamente justificable que ahora se abogue, en sustitución, por el "cientifico", entendido como el artífice de la peculiar "ciencia" más arriba descrita como crítica. El culto a las naturalezas excepcionales, a los "hombres grandes", pasa en cambio a ser tachado de infantilismo de la razón y acusado de devaluar el resto de los comportamientos humanos ordinarios.

En lo que concierne al segundo nivel, cabe resumir la evolución de la actitud nietzscheana como un desengaño o una desilusión con respecto a los personajes concretos, pero no tanto con respecto a los ideales, actitudes, tesis y proyectos que éstos parecían encarnar. Desde luego, no puede negarse que la caída de los modelos, su aprehensión tardía y retrospectiva como espejismos, repercute dolorosamente en las convicciones de Nietzsche. Pero, a pesar de la dramática pérdida de referencias, éste se esmera en distinguir adecuadamente los ideales de sus presuntos sustentadores que, en lo sucesivo, irán dejando paso a formulaciones más abstractas del perfil del artista dionisíaco, tales como la de espíritu libre. 
No deja de ser llamativo en todo caso el tono apocalíptico con que pretende reconocer en su público posicionamiento frente a Wagner y Schopenhauer la "suprema tarea del final, del cierre". Se trata del final de una pesadilla, que causa una indescriptible liberación. Y es que, como el propio Nietzsche habría de reconocer en el Post-Scriptum de El caso Wagner, una de las razones por las que el culto a Wagner se paga caro es porque se acaba reemplazando al mismo arte por el genio.

\section{El binomio Arte-Ciencia: La musa que ya no seduce}

La intención primera de este apartado, recapitulando problemas ya abordados, es incidir en la férrea coimplicación de los dos polos del binomio arte-ciencia, de tal forma que la suerte que cada uno de estos elementos corra en la consideración de Nietzsche determina y es determinada por la relevancia y la categoría atribuidas al otro elemento. En términos generales, puede afirmarse con Fink que el paso del primer al segundo Nietzsche viene marcado por un cambio de óptica: la óptica del arte, desde la que se interpretan los límites de la ciencia, viene a ser relevada por la óptica de la ciencia, desde donde serán interpretados los límites del arte. Ahora bien, para que semejante proceso especular no se antoje una inversión simplona obrada por un Nietzsche arrojado en brazos del positivismo, es preciso caer en la cuenta de algo esencial a mi juicio, que ninguno de los dos términos del binomio ha sido empleado antes ni lo será después en el mismo sentido.

Por lo que al arte se refiere, conocemos bien las notas definitorias del arte trágico-dionisíaco retratado por Nietzsche en NT. También hemos seguido algunas de sus disquisiciones en torno a las formas degeneradas del arte, las oposiciones entre el pequeño y el gran arte, entre un arte puro y vigoroso y otro viciado, engañador y débil, etc. Pues bien, creo que el Nietzsche que adopta la óptica del arte maneja ese concepto pleno, tan lejano al debilitado arte que aparece caricaturizado desde la posterior óptica 
de la ciencia. Desde esta segunda óptica, la oposición entre el arte y la ciencia equivale en realidad a la contraposición entre la debilidad y el vigor intelectuales. $Y$ sólo porque los referentes han cambiado sustancialmente se tornan comprensibles ciertas caracterizaciones que pueblan las páginas de obras como $\mathrm{HdH}$, como aquella que reconoce en los artistas a esos débiles de espíritu (Geistig-Weichlichen) incapaces de respirar el aire vivo propio de las ciencias.

Algo similar sucedería con el concepto de ciencia que en uno y otro caso se maneja. En el primer caso, se trata de la teoreticidad de corte socrático, que opondría al vigoroso hombre trágico la silueta de un empobrecido hombre teorético, ciego para las manifestaciones artísticas más profundas. En un segundo momento, el concepto de ciencia se enriquecería y ennoblecería con atributos de crítica perspicaz y desenmascaradora ante actitudes y manifestaciones engañosas y sucedáneas.

A esta fluida redefinición de rivales o interlocutores, si atendemos a los análisis de Fink, habría que añadir aún la oscilación en el concepto de vida, de una vida que sería lo persistentemente reivindicado pese al relevo de ópticas: "Lo único que ocurre es que el concepto de vida es entendido de manera diferente: primero, de modo cósmico-metafísico; y ahora, en forma psicológica y biológica." (EF, p.59)

Hasta aquí hemos suministrado un discreto arsenal de claves interpretativas, tales como las sucesivas muertes de lo trágico, la decadencia de la cultura moderna, el puesto privilegiado de la música en el arte, el papel estratégico de la música wagneriana, etc. Confío en que tales pautas hayan servido, cuando menos, para evitar lecturas precipitadas y simplistas del papel que el tópico de la muerte del arte desempeña en la obra de Nietzsche. El rastreo de este tópico ha invocado una multiplicidad de designaciones alternativas y casi intercambiables: ocaso, decadencia, degeneración, final, cierre, futuro sin arte, arte en retirada o, explícitamente, muerte. Todas estas expresiones pueden rastrearse en las páginas de escritos como Humano, demasiado humano, El caso Wagner, 
Pensamientos sobre Ricardo Wagner o Nietzsche contra Wagner. En nuestras manos está la lectura contextualizadora de estas consignas, encuadrándolas ya sea en la Grecia en vías de socratización, en la Alemania de Nietzsche, en el presagiado porvenir de Occidente, en su validez transtemporal o en su aplicabilidad a todo el decurso de nuestra cultura, desde la peculiar interpretación que el propio autor hace de nuestra evolución histórica.

En suma, las alusiones a la muerte del arte han forjado un contexto metafórico-alegórico, instrumentalizado en aras del perenne proyecto nietzscheano de crítica cultural. El vigor requerido para este proyecto motivará el que las metáforas reflejen una extraña mezcla de progresión evolucionista sentenciosa y despiadada, belleza quejumbrosa y ocasionales retazos de nostalgia.

Terminemos recordando aquel relato de Pausanias según el cual Pentesilea, reina de las Amazonas, combatió contra los griegos en el sitio de Troya y fue muerta por Aquiles, quien profirió lamentos sobre su cadáver y lloró al verla tan joven y bella. En cierto pasaje de la segunda parte de HdH, titulado precisamente "La musa como Pentesilea", Nietzsche aprovechará esta leyenda para fingir en la mente de la musa un pensamiento estremecedor: Lieber verwesen als ein Weib sein, das nicht reizt, es preferible pudrirse a ser una mujer que ya no seduce.

\section{BIBLIOGRAFIA PRINCIPAL}

DeLEUzE, Gilles, Nietzsche y la filosofia, 1971, Barcelona, Anagrama.

FINK, Eugen, La filosofia de Nietzsche, 1982, Madrid, Alianza Editorial.

MARCHÁN FIZ, Simón, La estética en la cultura moderna, 1987, Madrid, Alianza Forma, QUESADA, Julio, Un pensamiento intempestizo. (Ontologia, estética y política en F.

Nietzsche), 1988, Barcelona, Anthropos.

NIETZSCHE, Friedrich, Sämtliche Werke. Kritische Studienausgabe, Herausgegeben von

G. COLLI und Mazzino MONTINARI, vol. I, II, VI, VII, VIII y IX.

NiETzSCHE, Friedrich, El nacimiento de la tragedia, 1977, Madrid, Alianza Editorial.

Humano, demasiado humano, 1988, Madrid, EDAF. 
NIETzSCHE, Friedrich, Obras Completas, vol. III, IV y XI, 1954 ( $3^{\mathrm{a}}$ ed.), Buenos Aires, Aguilar

vol. III: Humano, demasiado humano (I)

vol. IV: Humano, demasiado humano (II) (incluye Pensamientos sobre Ricardo Wagner)

vol. XI: Ecce Homo. Arte y Artistas. El caso Wagner. Nietzsche contra Wagner.

\section{ABREVIATURAS EMPLEADAS}

NT: El nacimiento de la tragedia

$\mathrm{HdH}$ : Humano, demasiado humano

CI (I a IV): Consideraciones Intempestivas (I a IV)

SM : S. Marchán, La estética en la cultura moderna

GD : G. Deleuze, Nietzsche y la filosofia

EF: E. Fink, La filosofia de Nietzsche

JQ: J. Quesada, Un pensamiento intempestivo 